I. C. Packianathan - N. J. Fuller · D. B. Peterson •

A. Wright $\cdot$ W. A. Coward $\cdot$ N. Finer

\title{
Use of a reference four-component model to define the effects of insulin treatment on body composition in type 2 diabetes: the 'Darwin study'
}

Received: 22 June 2004 / Accepted: 15 September 2004 / Published online: 2 February 2005

(C) Springer-Verlag 2005

\begin{abstract}
Aims: To define the effects of insulin treatment on body composition and fat distribution, and investigate the potential role of body weight $(\mathrm{BWt})$ gain predictors in patients with poorly controlled type 2 diabetes. Methods: Assessments of body composition, using a four-component model, and biochemical indices were obtained in 19 patients [mean (SD): age, 60 (8.3) years; BMI, $25.3(3.3) \mathrm{kg} / \mathrm{m}^{2}$ ] with poorly controlled type 2 diabetes, despite maximal oral hypoglycaemic agents, receiving insulin [40 (12.2) units/day] at baseline and after 1,3 and 6 months. Results: Insulin therapy significantly reduced plasma glucose $[-6.0(4.3) \mathrm{mmol} / \mathrm{l}]$, improved
\end{abstract}

Duality of interest No duality of interest exist.

I. C. Packianathan $\cdot$ N. Finer

Wellcome Trust Clinical Research Facility and Department of

Endocrinology and Diabetes, Addenbrookes Hospital,

Hills Road,

Cambridge, CB1 2QQ, UK

I. C. Packianathan $\cdot$ N. Finer

Department of Diabetes and Endocrinology and Centre for

Obesity Research, Luton and Dunstable Hospital,

Lewsey Road,

Luton, LU4 0DZ, UK

N. J. Fuller $(\bowtie)$

MRC Childhood Nutrition Research Centre,

Institute of Child Health,

30 Guilford Street,

London, WC1N 1EH, UK

e-mail: N.Fuller@ich.ucl.ac.uk

Tel.: +44-207-9052397

Fax: +44-207-8319903

D. B. Peterson

Department of Diabetes and Metabolism,

Royal London Hospital,

Whitechapel,

London, E1 1BB, UK

A. Wright · W. A. Coward

Stable Isotope Group, MRC Human Nutrition Research,

Elsie Widdowson Laboratory,

Fulbourn Road,

Cambridge, CB1 9NL, UK
$\left[\mathrm{HbA}_{1} \mathrm{c}[-1.9(1.8) \%]\right.$, and reversed the BWt lost [3.3 $(1.8) \mathrm{kg}]$ before treatment. The 6-month BWt gain $[+5.2$ (2.7) $\mathrm{kg}]$ consisted of body fat $[+2.9(2.7) \mathrm{kg}]$ and fat-free mass [FFM; +2.3 (1.8) kg], with the FFM increase due solely to total body water [TBW; +2.4 (1.5) 1], as there were no detectable changes in total body protein or bone mineral, thereby increasing FFM hydration by $1.3 \%$. More body fat was deposited centrally in patients receiving insulin alone than those receiving insulin with an oral hypoglycaemic agent (metformin). Daily insulin dose, $\mathrm{HbA}_{1} \mathrm{c}$ and hip circumference were independent predictors of $\mathrm{BWt}$ gain. Conclusions: Insulin treatment increased fat and FFM similarly in poorly controlled type 2 diabetes patients, with the FFM gain due entirely to TBW. The possible role of metformin in reducing central fat accumulation following insulin treatment warrants further investigation into its mechanism and potential long-term benefits.

Keywords Body fat · Fat-free mass · Metformin Mineral $\cdot$ Total body protein $\cdot$ Total body water

Abbreviations 4-CM: Four-component model - BIA: Bioelectrical impedance analysis - BMC: Bone mineral content $\cdot \mathrm{BV}$ : Body volume $\cdot \mathrm{BWt}$ : Body weight $\cdot D_{\mathrm{ffm}}$ : Density of fat-free mass - DXA: Dual energy X-ray absorptiometry - FFM: Fat-free mass - FFST: Fat-free soft tissue $\cdot \mathrm{HF}_{\text {ffm }}$ : Hydration fraction of fat-free mass $\cdot \mathrm{TBW}$ : Total body water

\section{Introduction}

Clinical features of poorly controlled type 2 diabetes include fatigue, body weight (BWt) loss, polyuria, polydipsia and polyphagia. Initial treatment with dietary advice and oral hypoglycaemic agents aims to optimise glycaemic control, but many patients eventually require insulin treatment with increasing duration of their diabetes [1]. Although insulin is known to be associated with BWt increase $[2,3]$, few studies have examined the composition and distribution of BWt gain with insulin in type 2 diabetes. 
Some studies $[4,5]$ have shown an increase in fat-free mass (FFM), while others found an equal gain in both fat mass and FFM [6]. However, many of the techniques used in these studies have not been specifically validated for use in type 2 diabetes patients and rely on assumptions that may be inappropriate in type 2 diabetes. Most [7-9] used bioelectrical impedance analysis (BIA), while others used dual energy X-ray absorptiometry (DXA $[5,6]$ ) or tritiated water [10]. No study has yet applied a reference method suitable for assessing key features or changes in the FFM, such as its hydration fraction $\left(\mathrm{HF}_{\mathrm{ffm}}\right)$ or density $\left(D_{\mathrm{ffm}}\right)$. An increase in central fat mass has also been indicated [10], which is associated with cardiovascular disease and increased morbidity and mortality $[11,12]$. It is possible, therefore, that any increase in visceral fat deposition due to insulin treatment could offset the advantage of improved glycaemic control.

Although the reference four-component model (4-CM) that compartmentalises the body into fat, mineral [from bone mineral content (BMC)], total body protein and total body water (TBW), has been used to assess body composition in healthy adults [13], it has not been applied to type 2 diabetes. This 4-CM will be accurate for use in type 2 diabetes patients because it abolishes the need for assuming constant relationships among the major components of FFM that are inherent in other body composition models [13]. These include the various relationships between total body mineral (consisting of BMC and nonosseous mineral in assumed constant ratio), total body protein and TBW. The assumed constancy leads to the use of constant values derived for indices, such as $\mathrm{HF}_{\mathrm{ffm}}$ or $D_{\text {ffm. }}$. These values are almost always based on samples from healthy populations and are known to be associated with often substantial inter-individual variability and possible systematic biases if applied to sample groups exhibiting different characteristics (e.g. patients with type 2 diabetes). Another advantage of the 4-CM methodology is that DXA (used to measure BMC) can also be used to provide segmental estimates of fat and FFM.

Therefore, the aims of this study on insulin treatment in poorly controlled patients, on maximal oral hypoglycaemic drugs for type 2 diabetes, were: (1) to investigate the effects of insulin on body composition using a 4-CM; (2) to test the hypothesis that $\mathrm{BWt}$ gain is predominantly centrally deposited fat, representing potential increased health risks; and (3) to evaluate significant predictors of BWt gain with insulin therapy.

\section{Subjects and methods}

In this 6-month prospective study, patients were assessed at four time points: at baseline prior to the initiation of insulin (Month 0 ), after 4 weeks of treatment (Month 1), and again at 3 (Month 3) and 6 months (Month 6) follow-up. All measurements were performed by a single observer. Insulin was commenced within a week of the baseline assessment. The study was approved by the South Bedfordshire Local
Research Ethics Committee, and all subjects gave informed written consent prior to participation.

\section{Subjects}

Patients were recruited from the hospital Diabetes Clinic. The decision to commence insulin was taken by the patient's clinician, with the dose of insulin based upon the patient's BWt and level of hyperglycaemia. The inclusion criteria were as follows: (1) men and women with type 2 diabetes aged between 35 and 75 years; (2) fasting plasma glucose greater than $10 \mathrm{mmol} / \mathrm{l}$; (3) $\mathrm{HbA}_{1} \mathrm{c}$ greater than $8 \%$; and (4) receiving maximal doses of oral hypoglycaemic agents. Exclusion criteria were as follows: (1) uncontrolled hypertension, BP $>140 \mathrm{mmHg}$ systolic and $>95 \mathrm{mmHg}$ diastolic; (2) the presence of severe nephropathy; (3) any intercurrent illness, infection or malignancy; and (4) receipt of medication known to affect BWt regulation and appetite. All patients who initially volunteered $(n=26)$ provided a thorough medical history, had a physical examination and underwent laboratory investigation at baseline visit. Seven either did not complete the study or were withdrawn: one was lost to follow-up; one withdrew consent after family bereavement; three were excluded on medical criteria (one newly diagnosed subclinical hypothyroidism, one with $\mathrm{HbA}_{1} \mathrm{c}<8 \%$ and one nightshift worker requiring an insulin regimen change); one was withdrawn due to concurrent severe back pain necessitating clinical investigation; and one was excluded from the final analysis as measurements at baseline were implausible. Subjects attended the Research Centre at 08:00 hours, following a 10-h fast for all visits.

Demographic and laboratory characteristics, presented as mean (SD), of the 19 compliant subjects (14 male, five female; 13 Caucasian, five Asian, one Afro-Caribbean; five were smokers) at baseline were: age, 60.5 (8.3) years; duration of diabetes, 10.4 (5.1) years; fasting glucose, 14.3 (3.4) $\mathrm{mmol} / \mathrm{l} ; \mathrm{HbA}_{1} \mathrm{c}, 10.8$ (1.7)\%; serum free insulin, 5.8 (2.3) $\mathrm{mU} / \mathrm{l}$. Nine of the 19 patients had some degree of retinopathy, seven neuropathy and five microalbuminuria.

\section{Insulin regimen}

All subjects were commenced on a twice-daily regimen of either biphasic insulin lispro (Humalog Mix 25, six subjects) or biphasic isophane insulin (Human Mixtard 30, 13 subjects). The mean dose of insulin was 40 (12.2) units/day $\left(0.56\right.$ units $\left.\cdot \mathrm{kg}^{-1} \cdot \mathrm{day}^{-1}\right)$. Twelve patients received insulin alone.

A clinical decision was taken to continue metformin [1.8 (0.61) g/day] together with prescribed insulin (combination therapy group) for the other seven patients, in whom BMI was greater than $25 \mathrm{~kg} / \mathrm{m}^{2}$, because the use of metformin is considered to be of benefit for the overweight type 2 diabetes patient [14]. 


\section{Anthropometry}

BWt was measured to the nearest $0.1 \mathrm{~kg}$ on calibrated digital scales and height to the nearest $0.1 \mathrm{~cm}$ on a wallmounted stadiometer, from which BMI was calculated $\left(\mathrm{kg} / \mathrm{m}^{2}\right)$. Waist and hip circumferences were measured and the WHR calculated. Sagittal abdominal diameter was measured as the vertical distance in $\mathrm{cm}$ from the highest point on the abdomen to the back using a steel tape attached to a horizontal rule, with a spirit level anteriorly and a steel plate posteriorly.

\section{Body composition}

The reference 4-CM of body composition used in this study [13] combines measurements of BWt, body volume (BV; measured using air displacement plethysmography), TBW (estimated from deuterium dilution space) and BMC (measured using DXA):

$$
\begin{aligned}
\text { Body fat }(\mathrm{kg})= & 2.747 \mathrm{BV}-0.710 \mathrm{TBW}+1.460 \mathrm{BMC} \\
& -2.050 \mathrm{BWt} \\
\operatorname{FFM}(\mathrm{kg})= & \mathrm{BWt}-\text { Body fat }
\end{aligned}
$$

This 4-CM also allows calculation of a number of other informative indices including: fat mass index (body fat mass $/$ height $^{2} ; \mathrm{kg} / \mathrm{m}^{2}$ ), FFM index (FFM/height ${ }^{2} ; \mathrm{kg} / \mathrm{m}^{2}$ ), $D_{\text {ffm }}$ and $\mathrm{HF}_{\mathrm{ffm}}$, total body protein, total body mineral and total body protein as proportions of the FFM $(\%)$ and the protein/mineral ratio.

Air displacement plethysmography BV was measured using the Bodpod body composition system (Life Measurements Instruments, CA, USA), in strict accordance with manufacturer's instructions and recommendations [15]. The subjects wore tight-fitting swimming costumes and swimming caps. Essentially, BV was assessed by difference between the volume of air inside the anterior chamber of the instrument when empty and then with a subject present. Chamber air volume was measured using small pressure changes generated by an oscillating diaphragm located between the anterior and posterior chambers, using the relevant Gas Laws and taking account of ambient temperature and pressure [15]. In each test, duplicate measures of BV were performed, each lasting about $50 \mathrm{~s}$. If the two measurements differed by more than $150 \mathrm{ml}$ (manufacturer's determinant), a third measurement was performed. The average of the duplicate raw volume measurements, or the average of the closest two of three measurements, was used in subsequent calculations. Corrections were applied for surface area artefact and lung volume artefact, the latter based on predicted rather than measured values [16] as this procedure has been shown to be accurate and precise $[15,16]$. Body density (BWt/BV) was calculated from corrected BV.

Dual energy X-ray absorptiometry Measurements of BMC were obtained from the Lunar DPX-IQ model DXA instrumentation (Lunar Radiology, Madison, WI, USA). In essence, attenuation of X-rays at two distinct wavelengths enabled more accurate estimates of BMC to be obtained because the attenuation ratio of soft tissue is used primarily for correcting BMC for confounding effects of tissue overlying bone. This soft tissue attenuation ratio, therefore, also allowed the estimation of fat and fat-free soft tissue (FFST). Subjects were measured supine and wearing a light cotton gown with metal objects, such as jewellery, removed wherever possible. The procedure involved negligible radiation exposure and a high degree of precision appropriate for longitudinal studies [17, 18]. Analysis was performed using the Enhanced Body Composition software (version 4.7d) integral to the instrument that provided estimates of whole body and segmental composition. Limb muscle and limb adipose tissue masses were calculated from DXA segmental measurements of total limb mass, BMC, FFST and fat, using a theoretical model that takes into account the gross component content of the various tissues (for example, adipose tissue comprises up to about $80 \%$ fat, which is defined here as chemically extractable lipid) constituting the limb $[17,19]$. Limb muscle mass:

For women $(\mathrm{kg})=1.037$ Total limb mass -0.913 Skin mass -2.824 BMC -1.297 Fat mass

For men $(\mathrm{kg}) \quad=1.029$ Total limb mass -0.905 Skin mass -2.800 BMC

-1.286 Fat mass

Limb adipose tissue mass:

For women $(\mathrm{kg})=1.259$ Total limb mass -0.0869 Skin mass -2.042 BMC -1.292 FFST

For men $(\mathrm{kg}) \quad=1.256$ Total limb mass -0.9050 Skin mass -2.054 BMC -1.284 FFST

Estimates of limb skin mass were obtained using constant proportions of whole body surface area: $9 \%$ for each arm and 18\% for each leg [17].

Deuterium dilution A sample of saliva was collected from each subject in a salivette for the measurement of background (natural abundance) isotopic enrichment. An accurately weighed amount of dosing solution, nominally $100 \mathrm{~g}$ of $0.07 \mathrm{~g}$ deuterium oxide (99.9 APE-ck gas, Finchampstead, Berkshire, UK) per $\mathrm{ml}$ and previously passed through a $0.45-\mu \mathrm{m}$ syringe filter, was administered orally to each subject. Further saliva samples were obtained after 4, 5 and $6 \mathrm{~h}$. All salivettes were centrifuged to provide clear saliva samples for freezing at $-20^{\circ} \mathrm{C}$ until analysis. Deuterium enrichment in these samples and in sham-diluted dosing 
solutions was measured using isotope ratio mass spectrometry as previously described [20]. Pre- and post-dose saliva samples $(0.25 \mathrm{ml})$ were equilibrated for $6 \mathrm{~h}$ with 6 bar $\mathrm{ml}$ hydrogen gas in the presence of a platinum catalyst and then deuterium enrichment of the equilibrated gas measured by isotope ratio mass spectrometry. The difference between background and post-dose enrichment was used to calculate deuterium dilution space and TBW, determined using a correction factor (1.04) for non-aqueous exchange of deuterium in the body. Precision of the analyses for predose samples was $0.34 \mathrm{ppm}$ SD at an average of $154.32 \mathrm{ppm}$ and for post-dose samples was $0.69 \mathrm{ppm} \mathrm{SD}$ at an average of $320.54 \mathrm{ppm}$, equivalent to an error of $0.46 \%$ in the measurement of deuterium dilution space.

Laboratory analysis

All blood tests were performed on samples taken after a 10$\mathrm{h}$ fast. Plasma glucose was measured using the oxidase method and the Beckman glucose analyser (Synchron LX Systems, copyright 2000; Beckman Coulter, Inc.) [21]. Serum insulin was measured using a Microparticle Enzyme Immunoassay (Abbott Imx $\mathbb{C}$ Insulin assay), the sensitivity of which was $1.0 \mathrm{mU} / 1$, and cross-reactivity with proinsulin was $0.005 \%$. Prior to analysis, serum from insulin-treated patients was washed with polyethylene glycol to precipitate bound insulin and obtain free insulin [22]. $\mathrm{HbA}_{1} \mathrm{c}$ was measured using an ion-exchange high-pressure liquid chromatographic technique and expressed as $\% \mathrm{HbA}_{1} \mathrm{c}$ (DCCT equivalent) [23].

\section{Statistical analysis}

Initially, all analysis was undertaken on an intention-totreat basis. Subsequently, the group of patients receiving insulin alone $(n=12)$ and those on combination (insulin with metformin) therapy $(n=7)$ were analysed independently. Descriptive data are presented as mean (SD). All data from the 19 subjects fully completing the study were analysed using SPSS v.10. The ANOVA repeated measures method was used to analyse the effects of insulin treatment over time. A $p$ value of $<0.05$ was considered statistically significant. Pearson's correlation coefficient $(r)$ was used to examine the strength of relationships. Bivariate correlation analyses were performed between BWt gain and independent baseline variables including age, prestudy BWt loss, BWt, BMI, body composition, plasma glucose, insulin dose and $\mathrm{HbA}_{1} \mathrm{c}$, with partial
Table 1 Changes in anthropometric measurements and body composition indices, obtained using the four-component model, in type 2 diabetes patients treated with insulin $(n=19)$

\begin{tabular}{|c|c|c|c|c|c|}
\hline & $\begin{array}{l}\text { Month } 0 \\
\text { Mean (SD) }\end{array}$ & $\begin{array}{l}\text { Month } 1 \\
\text { Mean (SD) }\end{array}$ & $\begin{array}{l}\text { Month } 3 \\
\text { Mean (SD) }\end{array}$ & $\begin{array}{l}\text { Month } 6 \\
\text { Mean (SD) }\end{array}$ & $\begin{array}{l}\text { ANOVA } \\
p \text { value }\end{array}$ \\
\hline Body weight (kg) & $69.8(10.3)$ & $71.5(10.0)$ & $73.6(10.0)$ & $75.0(10.1)$ & $<0.0001$ \\
\hline BMI $\left(\mathrm{kg} / \mathrm{m}^{2}\right)$ & $25.3(3.5)$ & $26.0(3.1)$ & $26.7(3.0)$ & $27.2(3.0)$ & $<0.0001$ \\
\hline Waist (cm) & $89.6(8.4)$ & $90.6(8.5)$ & $93.3(8.2)$ & $94.9(8.1)$ & $<0.0001$ \\
\hline Hip (cm) & $96.8(8.0)$ & $97.9(7.6)$ & $99.3(6.9)$ & $98.9(6.6)$ & $<0.05$ \\
\hline WHR & $0.93(0.06)$ & $0.93(0.06)$ & $0.94(0.07)$ & $0.96(0.06)$ & $<0.001$ \\
\hline $\begin{array}{l}\text { Sagittal abdominal } \\
\text { diameter }(\mathrm{cm})\end{array}$ & $21.8(3.2)$ & $21.9(3.0)$ & $22.6(3.0)$ & $23.4(3.2)$ & $<0.0001$ \\
\hline Body density (kg/l) & $1.030(0.023)$ & $1.028(0.021)$ & $1.026(0.021)$ & $1.023(0.022)$ & $<0.0001$ \\
\hline Fat-free mass $(\mathrm{kg})$ & $48.1(9.5)$ & $49.2(9.6)$ & $50.3(10.0)$ & $50.4(10.2)$ & $<0.0001$ \\
\hline $\begin{array}{l}\text { Fat-free mass } \\
\text { index }\left(\mathrm{kg} / \mathrm{m}^{2}\right)\end{array}$ & $17.4(2.6)$ & $17.7(2.6)$ & $18.1(2.7)$ & $18.2(2.8)$ & $<0.0001$ \\
\hline $\begin{array}{l}\text { Total body } \\
\text { water (1) }\end{array}$ & $35.7(6.5)$ & $36.8(6.6)$ & $37.6(7.0)$ & $38.1(7.0)$ & $<0.0001$ \\
\hline Body fat (kg) & $21.7(6.2)$ & $22.3(5.8)$ & $23.3(6.1)$ & $24.5(6.5)$ & $<0.0001$ \\
\hline $\begin{array}{l}\text { Fat mass index } \\
\left(\mathrm{kg} / \mathrm{m}^{2}\right)\end{array}$ & $7.96(2.71)$ & $8.17(2.57)$ & $8.55(2.67)$ & $8.99(2.79)$ & $<0.0001$ \\
\hline Fat $(\%)$ & $31.1(9.0)$ & $31.3(8.5)$ & $31.9(8.9)$ & $32.9(9.2)$ & $<0.001$ \\
\hline $\begin{array}{l}\text { Bone mineral } \\
\text { content }(\mathrm{kg})\end{array}$ & $2.74(0.53)$ & $2.77(0.54)$ & $2.78(0.55)$ & $2.76(0.54)$ & $0.22(\mathrm{NS})$ \\
\hline $\begin{array}{l}\text { Density of fat-free } \\
\text { mass }(\mathrm{kg} / \mathrm{l})\end{array}$ & $1.101(0.009)$ & $1.098(0.009)$ & $1.098(0.009)$ & $1.095(0.008)$ & $<0.0001$ \\
\hline $\begin{array}{l}\text { Hydration of fat-free } \\
\text { mass }(\%)\end{array}$ & $74.33(2.37)$ & $74.88(2.43)$ & 74.90 (2.17) & $75.64(2.31)$ & $<0.001$ \\
\hline Total body protein (kg) & $8.97(2.60)$ & $8.97(2.74)$ & $9.18(2.64)$ & $8.93(2.83)$ & $0.5(\mathrm{NS})$ \\
\hline Mineral ( $\%$ fat-free mass) & $7.31(0.93)$ & $7.21(0.98)$ & $7.11(1.04)$ & $7.02(1.00)$ & $<0.001$ \\
\hline Protein ( $\%$ fat-free mass) & $18.36(2.34)$ & $17.91(2.65)$ & $17.99(2.23)$ & $17.34(2.55)$ & $<0.05$ \\
\hline Protein/mineral ratio & $2.56(0.49)$ & $2.55(0.58)$ & $2.59(0.52)$ & $2.54(0.58)$ & 0.8 (NS) \\
\hline
\end{tabular}


correlations obtained for all significant independent variables while controlling for each of the others in turn. A forward stepwise linear regression was undertaken to determine the predictors of $\mathrm{BWt}$ gain with insulin.

\section{Results}

Patients had markedly improved glucose control on insulin therapy. Fasting blood glucose levels decreased significantly from baseline $[14.3(3.4) \mathrm{mmol} / 1]$ at Month $1[-4.93$ (4.8) $\mathrm{mmol} / \mathrm{l} ; p=0.001]$, Month $3[-5.2$ (4.4) $\mathrm{mmol} / \mathrm{l}$; $p<0.001]$ and Month 6 [-6.0 (4.3) mmol/l; $p<0.001]$. $\mathrm{HbA}_{1} \mathrm{c}$ fell from $11.1 \%$ baseline to $9.2 \%$ at Month $3[-1.9$ $(1.8) \% ; p<0.001]$, remaining at $9.2(-1.9) \%$ at Month 6 $(p<0.001)$. Serum free insulin [5.8 $(2.3) \mathrm{mU} / 1$, baseline] was higher at Month $1[+2.0(2.5) \mathrm{mU} / 1 ; p=0.002]$, Month 3 $[+2.9(2.8) \mathrm{mU} / \mathrm{l} ; p=0.001]$ and Month $6[+3.2(3.5) \mathrm{mU} / \mathrm{l}$; $p=0.001]$.

There was a significant BWt loss of 3.3 (1.8) kg $(p<0.001)$ in the 3-6 months prior to baseline. Thereafter, following insulin therapy, the significant increase in $\mathrm{BWt}$ (Table 1) at Month $1[+1.7(1.6) \mathrm{kg}(2.4 \% \mathrm{BWt}) ; p<0.001]$, Month $3[+3.8(2.5) \mathrm{kg}(5.4 \% \mathrm{BWt}) ; p<0.001]$ and Month 6 $[+5.2(2.7) \mathrm{kg}(5.4 \%) ; p<0.001]$ was reflected in significant increases in BMI, waist and hip circumferences, the WHR and sagittal abdominal diameter at Month 6 (Table 1).

Table 1 also shows that there was a significant increase in body fat mass $[+2.9(2.7) \mathrm{kg} ; p<0.0001]$ and FFM $[+2.3$ (1.8) kg; $p<0.0001]$ over the period from Month 0 to Month 6 . The rate of body fat gain decreased slightly with time $(+0.6 \mathrm{~kg}$ from Month 0 to Month $1,+0.5 \mathrm{~kg} /$ month from Months 1 to 3 , and $+0.4 \mathrm{~kg}$ /month from Months 3 to 6 ). In contrast, most of the increase in FFM, almost entirely due to TBW, occurred during Month $1(+1.1 \mathrm{~kg})$, with a smaller increase between Months 1 and $3(+0.4 \mathrm{~kg} /$ month) and almost none between Months 3 and $6(+0.03 \mathrm{~kg} /$ month $)$.
$\mathrm{HF}_{\text {ffm }}$ increased significantly by $1.3 \%(p<0.0001)$ and $D_{\mathrm{ffm}}$ decreased by $0.006 \mathrm{~kg} / 1(p<0.001)$ to Month 6 , resulting from an increase in TBW [2.4 (1.5) 1] only, as total body protein and BMC remained unchanged. These changes were reflected in significant decreases in the relative proportions of protein and mineral in the FFM (Table 1) with the protein/mineral ratio remaining unchanged.

The BWt gain (Table 2) was observed to be mainly in the trunk $(+2.1 \mathrm{~kg}$ fat, $p<0.0001 ;+1.2 \mathrm{~kg}$ FFST, $p=0.006)$ and legs $(+0.7 \mathrm{~kg}$ fat, $p<0.0001 ;+0.5 \mathrm{~kg}$ FFST, $p=0.034)$, reflecting in part an increase in leg muscle mass $(0.3 \mathrm{~kg}$, NS). There was also a significant deposition of FFST (TBW) in the arms $(+0.24 \mathrm{~kg} ; p=0.003)$, representing a significant increase in arm muscle mass $(+0.21 \mathrm{~kg}$; $p=0.002$ ).

Comparing patients on insulin only with those on combination therapy showed a greater deposition of fat in the trunk with insulin alone $(+2.6 \mathrm{vs}+1.5 \mathrm{~kg} ; p<0.0001)$ and greater FFM deposition in the trunk for those on insulin + metformin $(+2.3 \mathrm{vs}+0.6 \mathrm{~kg} ; p=0.009)$. These differences in trunk fat weight or FFM were mirrored appropriately by changes in $\mathrm{BWt}$, body fat, $\mathrm{TBW}\left(\mathrm{HF}_{\mathrm{ffm}}\right)$ and FFM, with no changes in BMC or total body protein. In all other respects, there were no significant differences observed between sub-groups for any index of body composition for the insulin vs combination groups, men vs women or for the different races.

BWt gain at Month 6 was positively correlated with insulin dose $\left(r^{2}=0.64 ; p=0.003\right)$ and with baseline $\mathrm{HbA}_{1} \mathrm{c}$ $\left(r^{2}=0.46 ; p=0.04\right) . \mathrm{HbA}_{1} \mathrm{c}$ was also correlated with $\mathrm{BWt}$ gain while controlling for insulin dose, BMI, hip circumference and sagittal abdominal diameter. BWt at Month 3 correlated positively with insulin dose $\left(r^{2}=0.71 ; p=0.001\right)$ and negatively with hip circumference $\left(r^{2}=-0.58 ; p=0.01\right)$, independently of each other. The correlations with insulin dose were stronger for the insulin + metformin group (at Month 3, $r^{2}=0.89, p=0.008$; at Month 6, $r^{2}=0.96, p=0.001$ ).
Table 2 Changes in segmental composition based on dual-energy X-ray absorptiometry measurements for type 2 diabetes patients treated with insulin $(n=19)$

\begin{tabular}{lcllll}
\hline & $\begin{array}{l}\text { Month 0 } \\
\text { Mean (SD) }\end{array}$ & $\begin{array}{l}\text { Month 1 } \\
\text { Mean (SD) }\end{array}$ & $\begin{array}{l}\text { Month 3 } \\
\text { Mean (SD) }\end{array}$ & $\begin{array}{l}\text { Month 6 } \\
\text { Mean (SD) }\end{array}$ & $\begin{array}{l}\text { ANOVA } \\
p \text { value }\end{array}$ \\
\hline Trunk & & & & & \\
Fat-free soft tissue (kg) & $24.7(5.2)$ & $25.2(4.9)$ & $26.1(5.2)$ & $25.9(5.7)$ & $<0.01$ \\
Fat (kg) & $12.0(3.9)$ & $12.3(3.9)$ & $13.3(3.9)$ & $14.2(4.2)$ & $<0.0001$ \\
Bone mineral content (kg) & $0.82(0.18)$ & $0.85(0.20)$ & $0.86(0.21)$ & $0.87(0.17)$ & $0.36(\mathrm{NS})$ \\
Leg & & & & & \\
Muscle (kg) & $10.7(3.1)$ & $11.2(3.1)$ & $11.1(3.4)$ & $11.0(3.4)$ & $0.10(\mathrm{NS})$ \\
Fat-free soft tissue (kg) & $14.5(3.2)$ & $15.0(3.2)$ & $15.1(3.4)$ & $15.0(3.4)$ & $<0.05$ \\
Adipose tissue (kg) & $5.0(2.7)$ & $5.0(2.7)$ & $5.7(3.1)$ & $5.8(3.3)$ & $<0.0001$ \\
Fat (kg) & $5.0(2.0)$ & $5.1(2.0)$ & $5.6(2.3)$ & $5.7(2.5)$ & $<0.0001$ \\
Bone mineral content (kg) & $1.07(0.23)$ & $1.06(0.23)$ & $1.08(0.23)$ & $1.08(0.24)$ & $0.055(\mathrm{NS})$ \\
Arm & & & & & \\
Muscle (kg) & $3.4(1.3)$ & $3.6(1.3)$ & $3.6(1.2)$ & $3.6(1.2)$ & $<0.01$ \\
Fat-free soft tissue (kg) & $4.9(1.4)$ & $5.2(1.4)$ & $5.2(1.4)$ & $5.2(1.3)$ & $<0.01$ \\
Adipose tissue (kg) & $1.8(1.0)$ & $1.8(0.9)$ & $1.8(0.8)$ & $1.9(1.0)$ & $0.54(\mathrm{NS})$ \\
Fat (kg) & $1.8(0.8)$ & $1.8(0.7)$ & $1.8(0.6)$ & $1.9(0.8)$ & $0.56(\mathrm{NS})$ \\
Bone mineral content (kg) & $0.39(0.11)$ & $0.39(0.11)$ & $0.38(0.11)$ & $0.38(0.11)$ & $<0.03$ \\
\hline
\end{tabular}


The starting dose of insulin was a significant independent predictor of BWt gain at Month 6 explaining $41 \%$ of the variability $(p=0.006)$ with a further $22 \% \quad\left(r^{2}=0.66\right.$; $p=0.01)$ and $12 \%\left(r^{2}=0.84 ; p=0.003\right)$ accounted for by hip circumference and $\mathrm{HbA}_{1} \mathrm{c}$ respectively. At Month 3, the starting dose of insulin and hip circumference accounted for $68 \%$ of the variability $\left(r^{2}=0.68 ; p=0.003\right)$. Waist circumference, WHR and sagittal abdominal diameter were not important predictors of BWt gain.

\section{Discussion}

Weight gain is a frequent consequence of insulin treatment $[2,3]$, and fear of this may act as a deterrent to some patients. The components of this increased BWt have not been clearly defined; some studies have shown equal increases in fat and FFM [6], whereas others indicated the increase as predominantly FFM [5]. These discrepancies could result from differences in study populations (obese vs non-obese), insulin regimens (conventional vs intensive; continuous vs bolus) or the body composition methodology used (BIA [7-9], DXA [5, 6] or tritiated water dilution [10]). In contrast, use of the 4-CM [13] in this clinical study provided accurately assessed characterisation of the composition of BWt increases in a group of type 2 diabetes patients from the start of insulin therapy, along with a number of other clinically relevant indices (Table 1), and assessment of BWt distribution through the complementary use of DXA estimates of segmental composition [17, 19].

Underlying shifts in TBW may compromise the $\mathrm{HF}_{\mathrm{ffm}}$ in uncontrolled type 2 diabetes. Hyperglycaemia increases the osmotic pressure of the extracellular fluid, leading to a net movement of water from the cellular compartment into the extracellular fluid causing intracellular dehydration. At the same time, glycosuria may also cause decreased tubular reabsorption of fluid and concomitant extracellular fluid dehydration by osmotic diuresis [24]. In this study the $\mathrm{HF}_{\text {ffm }}$ at baseline was found to be within the normal range. However, insulin therapy, which decreases plasma glucose and glycosuria, still increased the $\mathrm{HF}_{\mathrm{ffm}}$ by a small but significant amount $(+1.3 \%)$, with no overt evidence of oedema. The increase in $\mathrm{HF}_{\mathrm{ffm}}$ was apparently due to an increase in TBW, since total body protein and $\mathrm{BMC}$ remained constant.

Some uncertainties remain in defining such changes in FFM. Firstly, the distribution of TBW between intracellular fluid and extracellular fluid was not measured in this study. Secondly, there may be insulin-induced changes in nonosseous mineral, which influence FFM estimates, but were not theoretically detectable using this $4-\mathrm{CM}$ in which a constant ratio of osseous to non-osseous mineral is assumed [13]. Originally based on cadaver dissection and chemical analysis [25], this assumption cannot be easily addressed with currently available in vivo technology. However, 4-CM estimates are robust to changes in this ratio [13]. Thirdly, the 4-CM is unable to define glycogen as an independent entity and, as its density approximates that of total body protein, glycogen is included in total body protein estimates [13]. Thus, any change in total body protein would not be recognised if there was a similar but contrasting change in glycogen, perhaps due to enhanced glycogenesis in response to insulin. This scenario is unlikely as the anabolic actions of insulin result in deposition of both protein and glycogen. Since these factors would only have small effects [13], the change in $\mathrm{HF}_{\text {ffm }}$ can be assumed to be water only, a contention which is supported by the concomitant decrease in $D_{\mathrm{ffm}}$, combined with the decrease in both mineral and protein content (\%) of FFM but without changes in the protein/mineral ratio (Table 1). If changes in either total body protein or BMC did occur over the longer term, they may not be detectable after the shorter 6-month period of this study.

BMI is an unreliable measure for tracking changes in adiposity in type 2 diabetes [26] as it represents total BWt and does not define in any way its main constituents, fat and FFM. Over the 6 months of insulin therapy, more than half $(56 \%)$ of the mean BWt increase was due to fat deposition (2.9 kg, estimated using the 4-CM) alone. This is probably undesirable, but the demonstration using DXA that the main fat deposition is within the trunk (about 2.2 of the $2.9 \mathrm{~kg}$ total fat increase) may be greater cause for concern if this is intra-abdominal, in terms of possible adverse metabolic sequelae. We have not directly demonstrated intra-abdominal or visceral fat accumulation, but the increases in waist circumference and sagittal abdominal diameter suggest visceral fat deposition, and are themselves linked to cardiovascular risk $[12,27]$.

In this study, the seven subjects coprescribed metformin showed a predominant deposition of FFM (TBW) in the trunk, in contrast to the 12 subjects on insulin alone who showed increased fat deposition. This differential body fat distribution could account for the beneficial effects of metformin in patients on insulin therapy [10, 14, 28, 29]. Furthermore, patients who are losing significant $\mathrm{BWt}$ prior to insulin therapy may be more likely to gain BWt than those who are not. This was shown when the data were subdivided into the insulin-only and combination therapy groups. The combination group was heavier overall than the insulin-only group [77.7 (11.0) vs $65.2(6.7) \mathrm{kg}$ ], and the BWt gain at 6 months was $+4.43(2.9)$ vs $+5.65(2.6)$ $\mathrm{kg}$, respectively, suggesting that the mechanism of BWt gain may be different in the heavier patients. However, the implications of these particular findings must be considered only preliminary as the combination therapy group was chosen on the basis of BMI above $25 \mathrm{~kg} / \mathrm{m}^{2}$, and not randomly selected from all those presenting with type 2 diabetes.

Insulin dose and $\mathrm{HbA}_{1} \mathrm{c}$ were independent predictors of BWt gain at Month 6 . The relationship between insulin dose and BWt gain is well described $[2,3]$, but that with $\mathrm{HbA}_{1} \mathrm{c}$ is more tenuous. For example, Henry et al. [30] found no correlation between the two, while Sinha et al. [5] found a negative correlation with FFM alone. This has significant therapeutic implications. Some clinicians are reluctant to prescribe insulin for type 2 diabetes because of the risk of weight gain and its adverse sequelae. Insulin is 
usually commenced when the patient has been diagnosed with a secondary failure of oral hypoglycaemic agents. The early institution of insulin when $\mathrm{HbA}_{1} \mathrm{c}$ levels are less elevated might limit BWt gain and improve insulin sensitivity [31]. Furthermore, BWt gain with insulin did not offset the beneficial effects of improved glycaemic control on metabolic risk, complications or quality of life $[6,32]$.

\section{Conclusions}

In summary, exogenous insulin therapy is associated with modest BWt gain at 6 months. The early BWt gain is due to both hydration and fat deposition with the latter period associated with fat deposition, predominantly in the truncal region. Metformin tends to a predominance of trunk FFM deposition. The exact mechanisms of BWt gain in type 2 diabetes patient needs further exploration.

Acknowledgements We thank Ruth Cornwell for the DXA measurements, John Wojdyla for the biochemical analyses, Jane Evans, Helen Hollern, Sandra Tomkins and Sharon White (Diabetes Specialist Nurses) who helped with recruitment of subjects, Penny Morris who provided some statistical advice and the study participants who gave so willingly of their time and effort.

\section{References}

1. Clauson P, Linnarsson R, Gottsater A, Sundkvist G, Grill V (1994) Relationships between diabetes duration, metabolic control and beta-cell function in a representative population of type 2 diabetic patients in Sweden. Diabet Med 11:794-801

2. The DCCT Research Group (1988) Weight gain associated with intensive therapy in the Diabetes Control and Complications Trial. Diabetes Care 11:567-573

3. Carlson MG, Campbell PJ (1993) Intensive insulin therapy and weight gain in IDDM. Diabetes 42:1700-1707

4. Birkeland KI, Hanssen KF, Urdal P, Berg K, Vaaler S (1994) A long-term, randomized, comparative study of insulin versus sulfonylurea therapy in type 2 diabetes. J Intern Med 236:305313

5. Sinha A, Formica C, Tsalamandris C et al. (1996) Effects of insulin on body composition in patients with insulin-dependent and non-insulin-dependent diabetes. Diabet Med 13:40-46

6. Bagg W, Plank LD, Gamble G, Drury PL, Sharpe N, Braatvedt GD (2001) The effects of intensive glycemic control on body composition in patients with type 2 diabetes. Diabetes Obes Metab 3:410-416

7. Leiter L (1996) Use of bioelectrical impedance analysis measurements in patients with diabetes. The Diabetes Control and Complications Trial Research Group. Am J Clin Nutr 64:515S$518 \mathrm{~S}$

8. Buscemi S, Blunda G, Maneri R, Verga S (1998) Bioelectrical characteristics of type 1 and type 2 diabetic subjects with reference to body water compartments. Acta Diabetol 35:220223

9. Tsui EY, Gao XJ, Zinman B (1998) Bioelectrical impedance analysis (BIA) using bipolar foot electrodes in the assessment of body composition in type 2 diabetes mellitus. Diabet Med 15:125-128

10. Groop L, Widen E, Franssila-Kallunki A et al. (1989) Different effects of insulin and oral antidiabetic agents on glucose and energy metabolism in type 2 (non-insulin-dependent) diabetes mellitus. Diabetologia 32:599-605
11. Hubert HB (1986) The importance of obesity in the development of coronary risk factors and disease: the epidemiologic evidence. Annu Rev Public Health 7:493-502

12. Larsson B, Seidell J, Svardsudd K et al. (1989) Obesity, adipose tissue distribution and health in men - the study of men born in 1913. Appetite 13:37-44

13. Fuller NJ, Jebb SA, Laskey MA, Coward WA, Elia M (1992) Four-component model for the assessment of body composition in humans: comparison with alternative methods, and evaluation of the density and hydration of fat-free mass. Clin Sci (Lond) 82:687-693

14. UK Prospective Diabetes Study (UKPDS) Group (1998) Effect of intensive blood-glucose control with metformin on complications in overweight patients with type 2 diabetes (UKPDS 34). Lancet 352:854-865

15. Dempster P, Aitkens S (1995) A new air displacement method for the determination of human body composition. Med Sci Sports Exerc 27:1692-1697

16. Wells JC, Fuller NJ (2001) Precision of measurement and body size in whole-body air-displacement plethysmography. Int J Obes 25:1161-1167

17. Fuller NJ, Laskey MA, Elia M (1992) Assessment of the composition of major body regions by dual-energy X-ray absorptiometry (DEXA), with special reference to limb muscle mass. Clin Physiol 12:253-266

18. Laskey MA (1996) Dual-energy X-ray absorptiometry and body composition. Nutrition 12:45-51

19. Fuller NJ, Hardingham CR, Graves M et al. (1999) Assessment of limb muscle and adipose tissue by dual-energy X-ray absorptiometry using magnetic resonance imaging for comparison. Int J Obes 23:1295-1302

20. Hoffman DJ, Sawaya AL, Coward WA et al. (2000) Energy expenditure of stunted and nonstunted boys and girls living in the shantytowns of Sao Paulo, Brazil. Am J Clin Nutr 72:10251031

21. Morrison B (1972) Use of the Beckman glucose analyser for low and high glucose values. Clin Chim Acta 42:192

22. Collins AC, Pickup JC (1985) Sample preparation and radioimmunoassay for circulating free and antibody-bound insulin concentrations in insulin-treated diabetics: a re-evaluation of methods. Diabet Med 2:456-460

23. Colman PG, Goodall GI, Garcia-Webb P, Williams PF, Dunlop ME (1997) Glycohaemoglobin: a crucial measurement in modern diabetes management. Progress towards standardisation and improved precision of measurement. Australian Diabetes Society, the Royal College of Pathologists of Australasia and the Australasian Association of Clinical Biochemists (consensus development conference). Med J Aust 167:96-98

24. Guyton AC (1991) Insulin, glucagon and diabetes mellitus. In: Textbook of medical physiology, 8th edn. WB Saunders Company, USA, pp 864-865

25. Brozek J, Grande F, Anderson JT, Keys A (1963) Densitometric analysis of body composition: revision of some quantitative assumptions. Ann N Y Acad Sci U S A 110:113-140

26. Looker HC, Knowler WC, Hanson RL (2001) Changes in BMI and weight before and after the development of type 2 diabetes. Diabetes Care 24:1917-1922

27. Pouliot MC, Despres JP, Lemieux S et al. (1994) Waist circumference and abdominal sagittal diameter: best simple anthropometric indexes of abdominal visceral adipose tissue accumulation and related cardiovascular risk in men and women. Am J Cardiol 73:460-468

28. DeFronzo RA, Barzilai N, Simonson DC (1991) Mechanism of metformin action in obese and lean noninsulin-dependent diabetic subjects. J Clin Endocrinol Metab 73:1294-1301

29. Makimattila S, Nikkila K, Yki-Jarvinen H (1999) Causes of weight gain during insulin therapy with and without metformin in patients with type II diabetes mellitus. Diabetologia 42:406412 
30. Henry RR, Gumbiner B, Ditzler T, Wallace P, Lyon R, Glauber HS (1993) Intensive conventional insulin therapy for type 2 diabetes: metabolic effects during a 6-month outpatient trial. Diabetes Care 16:21-31

31. Garvey WT, Olefsky JM, Griffin J, Hamman RF, Kolterman OG (1985) The effect of insulin treatment on insulin secretion and insulin action in type II diabetes mellitus. Diabetes 34:222234
32. Taylor R, Foster B, Kyne-Grzebalski D, Vanderpump M (1994) Insulin regimens for the non-insulin dependent: impact on diurnal metabolic state and quality of life. Diabet Med 11:551557 